\title{
Effect of Variation of Design Parameters on Cross Flow Turbine Efficiency Using ANSYS
}

\author{
Manchan Tiwari ${ }^{1}$, Rajendra Shrestha ${ }^{2}$ \\ ${ }^{1}$ Department of Mechanical Engineering, Kathmandu Engineering College, Kathmandu, Nepal \\ ${ }^{2}$ Department of Mechanical Engineering, Pulchowk Campus, IOE, TU, Lalitpur, Nepal \\ Corresponding author: ${ }^{1}$ manchantiwari@gmail.com, ${ }^{2}$ rsfluid@hotmail.com
}

Received: Jan 16, 2017 Revised: July 5, $2017 \quad$ Accepted: July 12, 2017

\begin{abstract}
Most of the major micro hydro power plants in Nepal uses Crossflow turbine for power generation which are manufactured locally. However, efficiency of these turbines has not been tested and verified. In this research, Cross flow turbine designs were obtained from local manufacturers. Efficiencies of these turbines were determined using simulation under steady state condition. Efficiencies were verified using the data from the installation site where these designs were used. Different Cross flow turbine models were prepared by varying the curvature radius of the blade and the ratio of inner to outer radius of the runner. The efficiencies of such models were determined using simulation.
\end{abstract}

Keywords: Cross flow turbine, efficiency, design parameters, blade angle

\section{Introduction}

The overall efficiency of a micro hydro power plant is considered in the range of 50 to 60 percentages. Turbine contributes to the major portion of the reduction of the overall efficiency in hydropower plant. The higher turbine efficiency would mean higher power output and consequently higher income for the same amount of investment. During 1996 to 2011, out of 308 numbers of Micro hydropower systems, 174 schemes used Cross flow turbines installed through Rural Energy Development Program (REDP) in Nepal [14].

Studies were performed to improve the efficiency of cross flow turbine. Effects of design parameters on the efficiency have been matter of extreme interest for researchers. There have been numbers of experimental researches testing the effects of variation of design parameters on the efficiency $[2,10,12,13,16,17]$. Most of the researches have followed the standard design where the outlet angle of the turbine blade is always $90^{\circ}$. The studies have tried to study the effect of variation of outlet angle of the blade on the efficiency by varying diameter ratio $[12,13]$. Research has also been done using commercial CFD code investigating the power output of cross flow turbine while varying inlet and outlet angles [17]. In the present study, a standard design model being using by manufacturers in Nepal is tested using CFD analysis. For other models, the diameter ratio and the radius of the blade curvature is varied to produce nine different models for the study. 


\section{Literature Review}

\subsection{Nomenclature and Design}

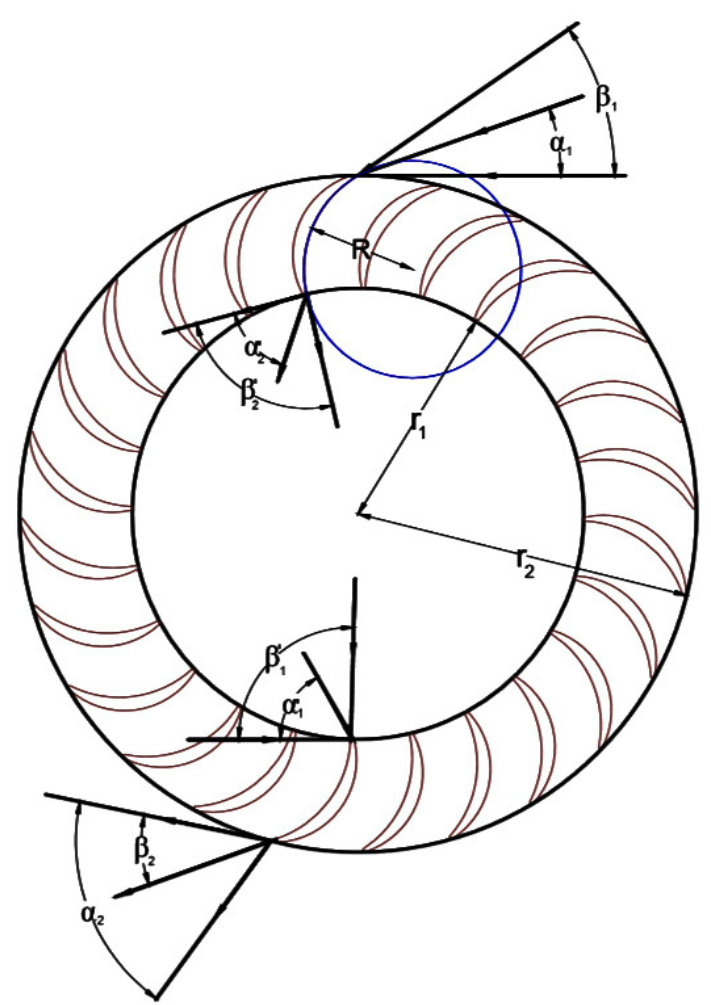

Fig.1: Cross flow Turbine Runner

- $\mathrm{R}$ is the radius of blade curvature

- $\quad \beta$ is the angle between relative velocity and peripheral velocity (also can be termed as angle between the tangent of the blade and runner periphery or blade angle)

- $\alpha$ represents the angle between absolute and peripheral velocity

- the sub-scripts ' 1 ' and ' 2 ' in case of $\alpha$ and $\beta$ represents inlet first stage and inlet second stage respectively

- the super-script 'I' in case of $\alpha$ and $\beta$ represents at the inside diameter of the wheel

- $r_{1}$ is the inner radius of the turbine runner

- $\mathrm{r}_{2}$ is the outer radius of the turbine runner

- $\mathrm{r}_{1} / \mathrm{r}_{2}$ is the diameter ratio

- $\mathrm{H}$ is the design head

- $\mathrm{Q}$ is the design flow

\subsection{Cross flow turbine design}

The cross flow turbine design prevailing in most manufacturers of Nepal was collected from Kathmandu Metal Industry, a leading designer of cross flow turbine in Nepal. The design is based for maximum head of $88 \mathrm{~m}$. The turbine was designed for $1500 \mathrm{rpm}$ and outer diameter of the turbine is taken $0.25 \mathrm{~m}$. The breadth of the turbine is $150 \mathrm{~mm}$. Design value of flow at maximum head was calculated to be $308 \mathrm{lps}$. The blade angle at inlet $\left(\beta_{1}\right)$ is $30^{\circ}$. The angle of attack $\left(\alpha_{1}\right)$ as 
given by the surface of the nozzle is $16^{\circ}$. The blade angle inside the runner $\left(\beta_{1}{ }^{\mathrm{I}}\right.$ and $\left.\beta_{2}{ }^{\mathrm{I}}\right)$ is $90^{\circ}$. The number of blades of the runner is taken 24 .

\subsection{Analyzing the design}

The major design parameters of the obtained design are based on design suggested in [7]. However, the improvement is done in the surface and structure of the blade which differs from the normal blade design used in cross flow turbines.

\subsection{Identifying design parameters to vary}

The blade angles inside the runner $\left(\beta_{1}{ }_{1}^{\mathrm{I}}\right.$ and $\left.\beta_{2}{ }^{\mathrm{I}}\right)$ are equal to each other as they are the angles given by the runner blade which is consistent throughout the runner. Also, $\alpha_{2}{ }_{2}^{\mathrm{I}}$ equals $\alpha_{1}{ }^{\mathrm{I}}$ for the same reasons [7]. Considering, the absolute velocity of water at outlet of first stage is equal to the absolute velocity of water at the inlet of second stage of runner, the relative velocity of water at the second stage of the runner equals to the resultant velocity of water at the outlet of first stage. Due to this, blade angle corresponds to the angle made by the relative velocity at the inlet of second stage $\left(\beta_{1}^{\mathrm{I}}=\beta_{2}^{\mathrm{I}}=90^{\circ}\right)$, so that there is no shock loss. However, the maximum efficiency is not a function of the angles $\beta_{1}{ }^{\mathrm{I}}$ and $\beta_{2}{ }^{\mathrm{I}}$. So, considering this fact, the blade angle was considered as the parameter to vary to study its effect on efficiency. The blade angle of the cross flow turbine could be varied by varying either the radius of curvature of the blade or the diameter ratio of the runner $\left(r_{1} / r_{2}\right)$ or both. The standard value of radius of curvature of the blade is $0.05 \mathrm{~m}$ and the diameter ratio is 0.67 . These parameters were varied with the purpose of testing its effect on the efficiency of the runner.

\section{Preparation of Different Models}

CAD model of the standard design obtained from Kathmandu Metal Industry was varied to obtain the nine different $\mathrm{CAD}$ models of the turbines. The varied parameters were radius of curvature of the blade and the diameter ratio. The radiuses of curvatures used were $0.045,0.05$ and $0.055 \mathrm{~m}$. The diameter ratios used were $0.6,0.67$ and 0.7 . Using these parameters, nine different models were made. The runner of the standard model was used for all varied runner models.

Table 1: Formulated Crossflow Turbine Models with Varying Design Parameters

\begin{tabular}{|c|c|c|c|}
\hline Model & Diameter Ratio $\left(\mathrm{r}_{1} / \mathrm{r}_{2}\right)$ & $\begin{array}{c}\text { Blade Curvature Radius } \\
(\mathrm{R})(\mathrm{m})\end{array}$ & Remarks \\
\hline 1 & 0.6 & 0.045 & \\
\hline 2 & 0.67 & 0.045 & \\
\hline 3 & 0.7 & 0.045 & \\
\hline 4 & 0.6 & 0.05 & \\
\hline 5 & 0.67 & 0.05 & Standard Model \\
\hline 6 & 0.7 & 0.05 & \\
\hline 7 & 0.6 & 0.055 & \\
\hline 8 & 0.67 & 0.055 & \\
\hline 9 & 0.7 & 0.055 & \\
\hline
\end{tabular}

For all the models the angle of attack and the number of blades were kept constant as that of the 
standard model. The outer radius of turbine is $250 \mathrm{~mm}$, the angle of attack is $16^{\circ}$ and the number of blades is 24 .

\section{Methodology}

\subsection{Rotor mesh preparation}

Among nine different models prepared, the rotor mesh was obtained using ANSYS Turbogrid. For the mesh preparation on turbogrid, the CAD model from AutoCAD was transferred to Catia V5 to obtain the co-ordinates of the blade, hub and shroud of each model of the cross flow turbine. Thus obtained co-ordinates were transferred in to a notepad file and consequently to Turbogrid to obtain the mesh files. The mesh for the casing of the runner was prepared using ANSYS Mesh.

\subsection{ANSYS CFX Setup}

The simulation of the rotor was done using ANSYS CFX on ANSYS Workbench as platform. The casing CAD file from Catia V5 was imported to ANSYS Design Modular. The mesh of the casing was produced using ANSYS ICEM CFD. Thus produced mesh file was used in ANSYS CFX along with the mesh file of the rotor produced from Turbogrid. The following major parameters were used for CFX Setup for the simulation of the nine formulated runner models.

- Analysis Type: Steady State

- Fluid: Water, Air

- Homogenous Model

- Turbulence: k-Epsilon

- Boundary Type: Mass Flow Inlet Pressure Static Outlet

- Mass Flow Inlet: $308 \mathrm{~kg} / \mathrm{s}$

- Pressure Static Outlet: $1 \mathrm{~atm}$

- Interface: Frozen Rotor

- Interface Type: Fluid

- Water Volume Fraction at Inlet: 1

- Air Volume Fraction at Inlet: 0

- Convergence: 0.0001

For the standard model, Transient analysis type was also used. Also for the standard model, different boundary conditions (Total Pressure Inlet Mass Flow Outlet and Total Pressure Static Inlet Pressure Outlet) were used to evaluate the efficiency under different boundary conditions. For the total pressure inlet, the value of pressure was taken as $862,207 \mathrm{kPa}$ which is equivalent of 88 $m$ maximum design head of the standard model of the turbine.

\subsection{Field Verification Data}

The power output testing data of three micro hydro sites were obtained where crossflow turbine was installed. The micro hydro powers were Nurkhuwa Micro Hydro Power System (Khotang District), RoshiKhola MHS (Kavre District) and SobuwaKhola MHS (Taplejung District) in Nepal. The data were used to estimate the efficiency of the crossflow turbines on the site. 


\section{Results and Discussion}

\subsection{Efficiency from onsite Power Output Testing}

The POT data were obtained for three sites as mentioned above. However, the data from RoshiKhola and NurkhuwaKhola were not reliable as the power testing did not yield stable results during different phase of testing. For the estimation of turbine efficiency, the generator efficiency and drive efficiency in assumed to be $80 \%$ and $95 \%$ respectively. The total power was measured by allowing the ballast load to consume all the produced power, and hence the turbine efficiency was calculated to be $71 \%$. This efficiency is low compared to the efficiency as mention in various literatures.

\section{Mesh Statistics of Rotor}

The mesh of a single blade obtained from turbogrid was transformed in to the mesh of rotor with 24 blades on ANSYS CFX Setup. The following table shows the mesh statistics of the rotors of all models as shown in CFX Setup.

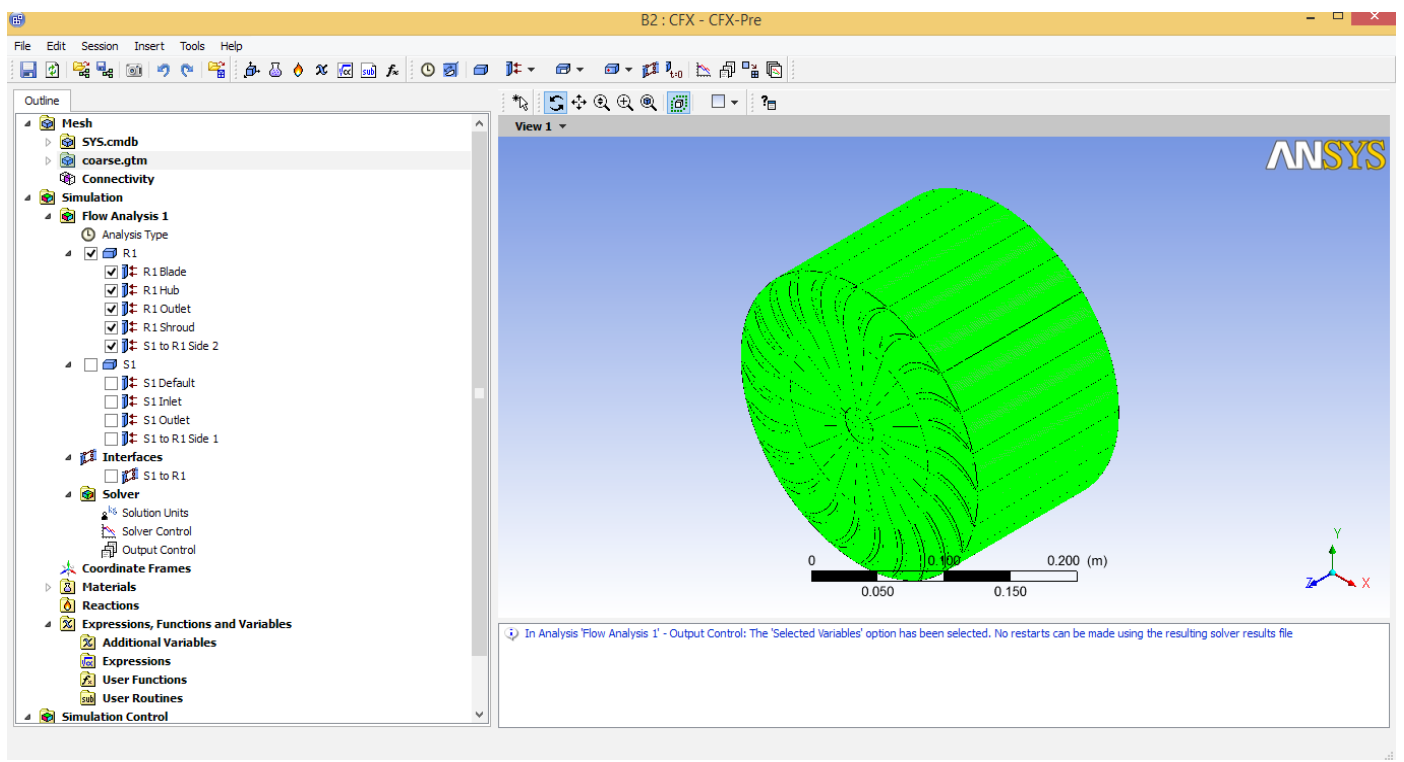

Fig. 2: Mesh Statistics of the Rotors

Table 2: Mesh Statistics for Different Rotor Models

\begin{tabular}{|c|c|c|c|}
\hline $\begin{array}{c}\text { Model } \\
\text { No. }\end{array}$ & $\begin{array}{c}\text { Total Number of } \\
\text { Nodes }\end{array}$ & Total Number of Elements & Total Number of Hexahedrons \\
\hline 1 & 3819024 & 3538080 & 3538080 \\
\hline 2 & 4342272 & 4040064 & 4040064 \\
\hline 3 & 4653792 & 4338432 & 4338432 \\
\hline 4 & 1322112 & 1164240 & 1164240 \\
\hline 5 & 4399824 & 4096512 & 4096512 \\
\hline 6 & 4283664 & 3984120 & 3984120 \\
\hline
\end{tabular}




\begin{tabular}{|l|l|l|l|}
\hline 7 & 3879744 & 3594528 & 3594528 \\
\hline 8 & 4260960 & 3960432 & 3960432 \\
\hline 9 & 1368576 & 1209600 & 1209600 \\
\hline
\end{tabular}

\subsection{Mesh Statistics of Casing}

The casing used for all rotors were same. The number of nodes in the mesh of the casing was 44,478 . Total number of elements was 36960 out of which total numbers of prism were 640 and total numbers of hexahedrons were 36320 .



Fig. 3: Mesh Statistics of the Casing

\subsection{Efficiency of Rotors}

The power developed at the shaft of the runners and the hydraulic power was calculated using the following expression in ANSYS CFD Post.

Pshaft $=$ torque $_{Z()} @ R 1$ Blade $* 2 * P i * \frac{\text { omega }}{360}[$ degree $]$

Phydraulic $=($ massFlowAve $($ Pressure $) @ S 1$ Inlet - massFlowAve $($ Pressure $) @ S 1$ Outlet $) *$ massFlow ()S1 $\frac{\text { Inlet }}{1000}\left[\frac{\mathrm{kg}}{\mathrm{m}^{3}}\right]$

The efficiency was calculated using following expressions.

Efficiency $=\frac{\text { Pshaft }}{\text { Phydraulic }} * 100$ 
Table 3: Efficiency of Different Models

\begin{tabular}{|c|c|c|c|c|c|}
\hline $\begin{array}{c}\text { Model } \\
\text { Number }\end{array}$ & $\mathrm{P}_{\text {shaft }}($ Watt $)$ & $\mathrm{P}_{\text {hydraulic }}$ (Watt) & Efficiency (\%) & $\left(\mathrm{r}_{1} / \mathrm{r}_{2}\right)$ & $\begin{array}{c}\text { Radius of curvature of } \\
\text { Blade }\end{array}$ \\
\hline 1 & 291178 & 442005 & 65.87 & 0.6 & 45 \\
\hline 2 & 290456 & 434105 & 66.9 & 0.67 & 45 \\
\hline 3 & 289469 & 430097 & 67.3 & 0.7 & 45 \\
\hline 4 & 291282 & 438678 & 66.4 & 0.6 & 50 \\
\hline 5 & 294107 & 437966 & 67.153 & 0.67 & 50 \\
\hline 6 & 288130 & 434807 & 66.26 & 0.7 & 50 \\
\hline 7 & 291415 & 448552 & 64.96 & 0.6 & 55 \\
\hline 8 & 287809 & 443486 & 64.897 & 0.67 & 55 \\
\hline 9 & 290155 & 438964 & 66.1 & 0.7 & 55 \\
\hline
\end{tabular}

\subsection{Variation of Efficiency}

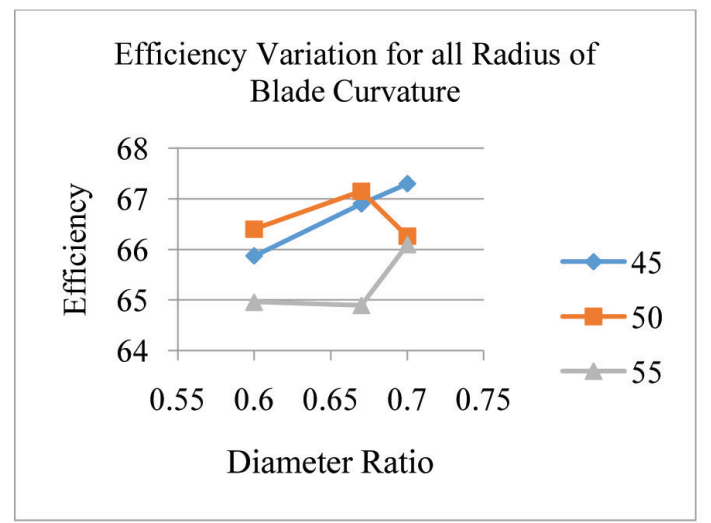

Fig. 4: Efficiency variation of different model

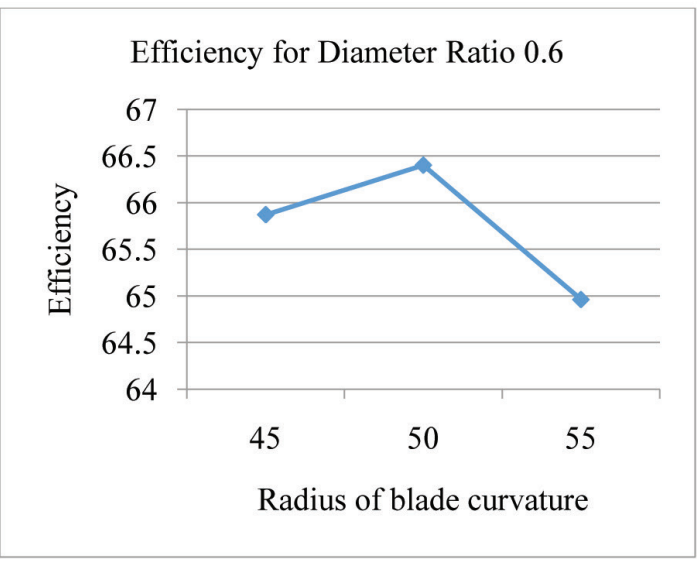

Fig. 5: Efficiency for Diameter Ratio 0.6



Fig.7: Efficiency for radius of blade curvature 45 mm

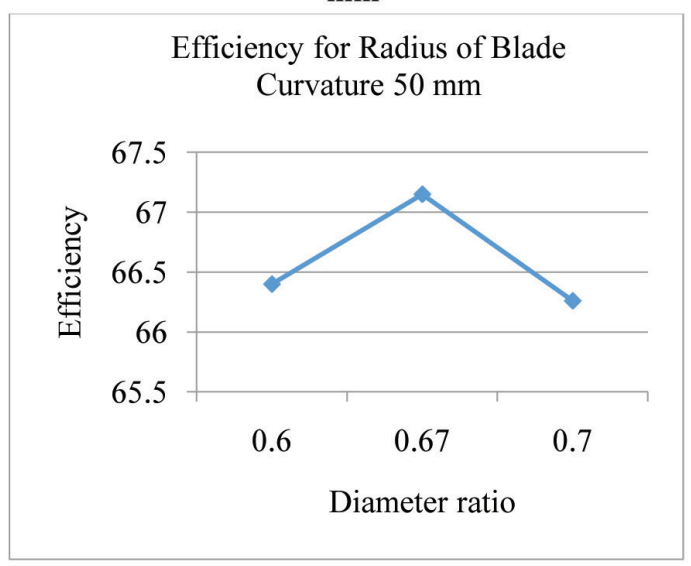

Fig. 8: Efficiency for Radius of Blade Curvature $50 \mathrm{~mm}$ 


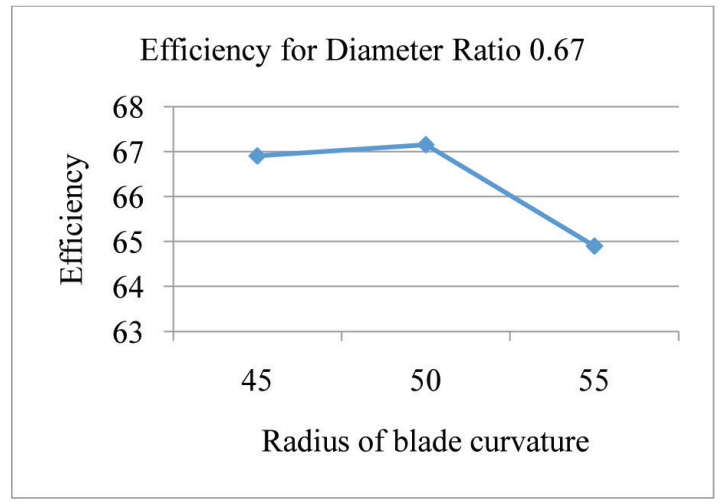

Fig. 6: Efficiency for Diameter Ratio 0.67



Fig. 9: Efficiency for Radius of Blade Curvature $55 \mathrm{~mm}$

The efficiency vs. diameter ratio graph for different blade curvature radius does not show a common pattern for efficiency variation for the different radius. However, by varying the radius of blade curvature and diameter ratio the efficiency is increased in case of blade curvature radius $0.055 \mathrm{~m}$ and diameter ratio 0.7 .

\section{Conclusion}

Among the various Cross flow turbine models which were prepared by varying the design parameters, most efficient model was found to be Model 3 which has radius of blade curvature $0.045 \mathrm{~m}$ and diameter ratio 0.7 . The efficiency of the Model 3 is $67.3 \%$. The design value is different from that of the standard design which has $0.05 \mathrm{~m}$ blade curvature radius and diameter ratio of 0.7 . The efficiency of the standard model (Model 5) was found to be $67.15 \%$ in steady state simulation. The onsite data yielded efficiency as $71 \%$ which was close to the result from the simulation. Conclusion that can be derived from this research is that the efficiency has increased at outlet angle which is different from traditional angle of $90^{\circ}$. This conclusion is supported by the conclusion derived by Young Do Choi [17] where the research shows that the power produced in the second stage of the cross flow turbine is highest in case of outlet angle of $80^{\circ}$. It implies that the power produced in the second stage of the turbine is greater when the outlet angle deviates further away from $90^{\circ}$. In this research, the total power in both first and second stage is highest with lowest inlet angle and outlet angle of $87^{\circ}$.

The variation of parameters has led to increase in efficiency even though the increased value is insignificant. As the value of the varied design parameters were taken to the close proximity of the standard design values, the results shows room for improvement of the efficiency by taking wide range of variation of the radius of blade curvature and the diameter ratio. The maximum efficiency is also dependent upon the angles $\beta_{1}$ ' and $\beta_{2}$ ' so, more relevant theory and experimental verification is required to identify the optimum values of $\beta_{1}$ ' and $\beta_{2}$ ' for maximum efficiency.

\section{References}

[1] ANSYS Workbench User's Guide (2009, November), Southpointe, Canonsburg, USA: ANSYS, Inc.

[2] Fiuzat AA (1989). The use of interior guide tube in cross flow turbine. Waterpower, 89(2): 11111119 . 
[3] Abbas A and Fiuzat BP (1991), Power outputs of two stages of cross-flow turbine. Journal of Energy Engineering, 117(3):57-70 .

[4] ANSYS, Inc. (2011, November), ANSYS FLUENT Theory Guide. Southpointe, Canonsburg, USA.

[5] ANSYS, Inc. (2011, November), ANSYS FLUENT User's Guide. Southpointe, Canonsburg, USA.

[6] Bryan Ho-Yan WD (2011), Performance Evaluation of Cross-Flow Turbine for Low Head Applications. World Renewable Energy Congress (pp. 1394-1399). Linkoping, Sweden: Hydropower Applications.

[7] Mockmore CA (1949), The Banki Water Turbine. Corvallis: Engineering Experiment Station, Oregon State College.

[8] Harvey A (1993), Micro-Hydro Design Manual: A guide to small-scale power schemes. London: Intermediate Techonology Publications.

[9] Helena M and Ramos MS (2012), Low- Head Energy Conversion: A Conceptual Design and Laboratory Investigation of a Microtubular Hydro Propeller. International Scholarly Research Network.

[10] Jusuf Haurissa SW (2012), The Cross Flow Turbine Behaviour towards the Turbine Rotation Quality, Efficiency and Generated Power. Journal of Applied Sciences Research, 8(1): 448-453.

[11] Khalifa D (2013), Simulation of an Axial Flow Turbine Runner's Blades using CFD. International Journal of Current Engineering and Technology, 3(2): 234-238.

[12] Nadim M Aziz VR (1993), A laboratory study to improve the efficiency of cross-flow turbines. Department of Civil Engineering, Clemson University.

[13] Nadim M Aziz VR (1993), An experimental study of the effect of some design parameters on cross-flow turbine efficiency. Department of Civil Engineering, Clemson University.

[14] Rural Energy Development Programme. (2011), Achievements of REDP 16th August, 1996 to 31st March, 2011. Lalitpur: REDP NEP/07/011.

[15] Walseth EC (2009), Investigation of the Flow through the Runner of a Cross-Flow Turbine. Norwegian University of Science and Technology.

[16] Young Do CHOI (2008), Performance and Internal Flow Characteristics of a Cross-Flow Hydro Turbine by the Shapes of Nozzle and Runner Blade. Journal of Fluid Science and Technology, 3(3): 398-409.

[17] Young Do Choi, J.-I. L.-T.-H. (2008), Effect of Blade Angle on the Performance of a Cross-Flow Hydro Turbine. Journal of the Korean Society of Marine Engineering, 32(3): 413-420. 